\section{Polarization of Comet Arend-Roland}

When, last May, Comet Arend-Roland became a bright naked-eye object in the northern hemisphere, we carried out a series of photoelectric measures of the polarization of its coma at different phase angles. The technique employed utilized a piece of 'Polaroid' attached to a rotatable six-position disk contained in the photometer. This enables measurements of intensity to be made as the 'Polaroid' is turned through 60 deg. for each position of the disk. Standard $B$ and $V$ filters employed in the $U B V$ system, together with interference filters having peak transmissions centred on $5890 \mathrm{~A}$, $5000 \mathrm{~A}$., $4700 \mathrm{~A}$. and $4300 \mathrm{~A}$. and half-widths of $80 \mathrm{~A}$. were used for isolating the different wave-lengths. Each of the three circular apertures behind the 'Polaroid' transmitted 3.7 square minutes of arc of the sky.

We have calculated the amount of polarization and plane of polarization, from at least six sets of measures, each day, for radiation transmitted by each filter, a set of deflexions being considered as those obtained through three successive positions of the 'Polaroid'. Since, in each position of the 'Polaroid', the light reaches the photomultiplier through a diaphragm and area of the 'Polaroid' different from that of the previous position, we determined correction factors by measures of bright nearby stars, and applied these to the cometary measures. The orientation of the 'Polaroid' was determined by a laboratory arrangement, and we believe that the error in transferring this plane of reference to the telescope does not exceed $1 \mathrm{deg}$. The probable error of the value of percentage polarization is estimated to be less than \pm 1 per cent and that of a value of the plane of polarization to be $\pm 5 \mathrm{deg}$. The values derived for $5890 \mathrm{~A}$., $5000 \mathrm{~A}$., and $4700 \mathrm{~A}$. are given in Table 1. These values cover a limited range of phase angle because the comet, after May 8, was beyond the range of accurate measurement with our interference filter - 'Polaroid' combination.

Table 1

\begin{tabular}{|c|c|c|c|}
\hline \multirow{2}{*}{$\begin{array}{c}\text { Date } \\
\text { May } 1957\end{array}$} & \multicolumn{3}{|c|}{$\begin{array}{l}\text { Percentage polarization and } \\
\text { position angle of plane of polarization }\end{array}$} \\
\hline & 5890 A. & 5000 A. & $4700 \mathrm{~A}$ \\
\hline $\begin{array}{l}4 \cdot 658 \\
5 \cdot 641 \\
6 \cdot 648 \\
7 \cdot 655 \\
8 \cdot 660\end{array}$ & $\begin{array}{l}17 \cdot 5 \\
103^{\circ} \\
17 \cdot 4 \\
116^{\circ} \\
19 \cdot 7 \\
119^{\circ} \\
12 \cdot 9 \\
121^{\circ} \\
20 \cdot 5 \\
123^{\circ}\end{array}$ & $\begin{array}{c}- \\
18 \cdot 0 \\
112^{\circ} \\
15 \cdot 0 \\
117^{\circ} \\
14 \cdot 1 \\
124^{\circ} \\
20 \cdot 0 \\
123^{\circ}\end{array}$ & $\begin{array}{c}17 \cdot 9 \\
107^{\circ} \\
20 \cdot 4 \\
114^{\circ} \\
17 \cdot 3 \\
119^{\circ} \\
16 \cdot 8 \\
12 \cdot 2^{\circ} \\
14.5 \\
-\end{array}$ \\
\hline
\end{tabular}

The measures of polarization through the $B$ and $V$ filters cover a larger phase angle than with the interference filters. Table 2 contains values of the amount of polarization and the plane of polarization for each day obtained through the $V$-filter, along with those of phase angle and position angle of the intensity equator that were calculated from the emphemeris of Candy ${ }^{1}$. A general decrease in amount of polarization with phase angle, along with superimposed erratic fluctuations from day to day of the order of 2-3 per cent, is seen. Assuming that the relation between amount of polarization and phase angle is given by

$$
P_{\theta}=\frac{P_{90} \sin ^{2} \theta}{1+P_{9 \theta} \cos ^{2} \theta}
$$

Table 2

\begin{tabular}{|c|c|c|c|c|}
\hline $\begin{array}{c}\text { Date } \\
\text { May 1957 }\end{array}$ & $\begin{array}{c}\text { Percentage } \\
\text { polariza- } \\
\text { tion }\end{array}$ & $\begin{array}{l}\text { Position angle } \\
\text { of plane of } \\
\text { polarization }\end{array}$ & $\begin{array}{l}\text { Phase } \\
\text { angle }\end{array}$ & $\begin{array}{l}\text { Position angle } \\
\text { of intensity- } \\
\text { equator }\end{array}$ \\
\hline $\begin{array}{r}4 \cdot 658 \\
5 \cdot 641 \\
6 \cdot 648 \\
7.655 \\
8 \cdot 660 \\
11.656 \\
1+\cdot 662 \\
15 \cdot 662 \\
22 \cdot 647 \\
26 \cdot 650\end{array}$ & $\begin{array}{r}18 \cdot 9 \\
18 \cdot 3 \\
19 \cdot 9 \\
17 \cdot 0 \\
14 \cdot 5 \\
12 \cdot 8 \\
14 \cdot 0 \\
15 \cdot 3 \\
9 \cdot 6 \\
6.2\end{array}$ & $\begin{array}{l}104^{\circ} \\
111^{\circ} \\
116^{\circ} \\
119^{\circ} \\
120^{\circ} \\
129^{\circ} \\
148^{\circ} \\
135^{\circ} \\
147^{\circ} \\
148^{\circ}\end{array}$ & $\begin{array}{l}76^{\circ} 24^{\prime} \\
73^{\circ} \mathbf{4 7}^{\prime} \\
71^{\circ} 12^{\prime} \\
68^{\circ} 48^{\prime} \\
66^{\circ} 36^{\prime} \\
60^{\circ} 41^{\prime} \\
55^{\circ} \mathbf{4 5} \\
54^{\circ} 16^{\prime} \\
45^{\circ} \mathbf{4 4}^{\prime} \\
\mathbf{4} 1^{\circ} \mathbf{5 4 ^ { \prime }}\end{array}$ & $\begin{array}{l}37^{\circ} 48^{\prime} \\
40^{\circ} 01^{\prime} \\
42^{\circ} 12^{\prime} \\
44^{\circ} 16^{\prime} \\
46^{\circ} 13^{\prime} \\
51^{\circ} 21^{\prime} \\
55^{\circ} 25^{\prime} \\
56^{\circ} 32^{\prime} \\
62^{\circ} 00^{\prime} \\
63^{\circ} 37^{\prime}\end{array}$ \\
\hline
\end{tabular}

where $P_{0}$ and $P_{80}$ are the values at phase angles $\theta$ and $90^{\circ}$ respectively, we have calculated the values of $P_{30}$ for the comet through the different filters. These are seen to be consistent among themselves.

The 5890-A., 5000-A., 4700-A. interference filters were chosen to isolate the Swan bands present in the spectrum of the Comet. A check on the continuum was maintained with the aid of the 4300 -A. filter. The $V$-filter transmits, in the yellow and green regions, the $C_{2}$ radiations and possible sodium $D$-line emission together with the continuum of reflected sunlight. Hence, a value of the polarization of the coma determined through the $V$-filtor represents a weighted mean of the percentage of polarization of the emission bands as well as of the continuum. The equality in the values of $P_{90}$ derived through the different filters used, indicates the dominant part played by the continuum. We have had no access to spectra of the Comet taken on these days, but judging from Wellman's ${ }^{2}$ description of the spectrum as it appeared on April 23, the emission may have been very weak during the period we observed. The polarization of Comet Arend-Roland is thus similar to that of Comet Paraskevopoulos (1941c) studied by Ohman $^{3}$.

Within the errors of measurement, the planes of polarization at any one time of observation obtained through the different filters are all identical. Table 2 shows that the change in plane of polarization with time is linear, though it is more rapid than the change in position angle of the intensity-equator during the same time interval.

M. K. VaInu Bappu

S. D. Sinvelat

Uttar Pradesh State Observatory, Naini Tal.

Aug. 6.

${ }^{1}$ Candy, M. P., Int. Astron. Union Circ. No. 1585 (Feb. 20, 1957). 2 Wellman, P., Int. Astron. Union Circ. No. 1596 (April 29, 1957). ohman, Y., Stockholm Annals, 13, No. 11 (1941).

\section{Crystal Structure of Oximes}

THE crystal structure of syn-p-chlorobenzaldoxime has been determined in more detail than previously reported ${ }^{1}$ by a three-dimensional Fourier-synthesis and two-dimensional $F_{0}-F_{c}$-syntheses. The main features of the structure are shown in Fig. 1. The hydrogen atoms connected to the carbon atoms were found in the expected positions, although their parameters could not be determined accurately. There was fairly conclusive evidence from the electron-density maps that the hydrogen atom of the oxime group is covalently bound to oxygen; the 